\title{
HUBUNGAN ANTARA PENGAWASAN DAN KOMPENSASI DENGAN PRESTASI KERJA GURU DI SMA NEGERI SE-KOTA BEKASI
}

\author{
Mukaromah* $^{*}$
}

\begin{abstract}
This research aims to determine the relationship between (1) control with teacher's performance at public SMA in Bekasi,Districk (2) compensation with teacher's performance at public SMA in Bekasi,Districk, (3) control and compensation together with teacher's performance at public SMA in Bekasi Districk. The research method using survey by correlational approach. This research used sample of 90 employees (teachers and principals), and 20 employees (teachers and principals) for trial, and selected based on a simple random technique (Simple Random Sampling). Study toward in public Senior High School in Bekasi Districk. Technique data collecting was using the instrument in the form of questionnaire. This instrument is calibrated with the test item validity and reliability coefficients. To test the validity of using Pearson Product Moment correlation, while the reliability coefficient is calculated using the formula of Cronbach Alpha.

The results showed that: First, there is a positive relationship between control with performance. Secondly, there is a positive relationship between compensation with the performance. Third, there is a positive relationship between control and compensation together with performance. The implications of this research is teacher's performance in Bekasi can be enhanced through control of the Principal and an increase in compensation.
\end{abstract}

Keywords : Compensation, Control, Performance

\section{PENDAHULUAN}

Kemajuan suatu bangsa sangat ditentukan oleh tingkat sumber daya manusianya, sedangkan kualitas sumber daya manusia sangat ditentukan oleh tingkat pendidikan masyarakatnya. Dalam meningkatkan SDM, guru merupakan ujung tombak dalam dunia pendidikan, khususnya di sekolah. Peran guru menempati posisi strategis dalam setiap usaha perbaikan mutu pendidikan. Dengan demikian, .prestasi kerja guru merupakan salah satu elemen penting dalam meningkatkan kualitas pendidikan.

Prestasi kerja guru dapat dilihat dari apa yang dilakukan oleh seorang guru dan bagaimana cara menyelesaikan setiap pekerjaannya. Hal ini sejalan dengan pendapat Wibowo (2009: 7) bahwa prestasi kerja bukan hanya hasil kerja, tetapi termasuk bagaimana proses pekerjaan berlangsung. Selain itu, peran guru sebagai tenaga pendidik tidak hanya berhenti sebagai pemegang tonggak peradaban saja, tetapi juga melahirkan peradaban bagi kemajuan zaman

Berbagai upaya dilakukan pemerintah untuk meningkatkan prestasi kerja guru diantaranya program penataran, pendidikan pelatihan, program beasiswa pendidikan, dan program peningkatan profesi pendidik lainnya. Akan tetapi program-program tersebut belum secara optimal meningkatkan prestasi kerja guru. Indikator yang mengarah ke sana adalah masih rendahnya nilai ujian nasional bahkan masih banyak siswa yang tidak lulus ujian nasional. Pada tahun 2010 tingkat kelulusan Ujian Nasional (UN) siswa SMA dan MA secara nasional menurun 4 persen dibanding 2009, yakni dari 93,74 persen menjadi 89,88 \% (http://metrotvnews.com). Selanjutnya, anggota DPRD

* Ketua LITBANG SMA Negeri 1 Kota Bekasi 
DKI Jakarta juga mengatakan angka kelulusan merupakan tolok ukur dari kualitas pendidikan termasuk kinerja guru (http:// www.suarakarya-online.com).

Kementerian Pendidikan Nasional (Kemendiknas) terus berupaya meningkatkan kualitas tenaga pendidik, Muhammad Nuh berharap kualitas guru semakin meningkat sejalan dengan rencana strategi (renstra) Kemendiknas 2011-2014. Salah satunya adalah memperluas dan mempercepat peningkatan kualifikasi akademik guru, sertifikasi, dan rintisan pendidikan profesi guru. Dengan program ini, diharapkan semakin besar kesempatan para guru untuk meningkatkan kualitasnya (http://www.radarbanten.com).

Berdasarkan kenyataan di atas, maka Kota Bekasi sebagai wilayah penyangga ibu kota dengan jumlah penduduk 2.327.705 jiwa, terus melakukan terobosan dengan memperbaiki infrastruktur pendidikan yang lebih memadai. Seiring dengan pertumbuhan penduduknya yang semakin pesat, Kota Bekasi membangun sarana dan prasarana pendidikan dari SD hingga SMA yang tersebar dalam dua belas wilayah kecamatan. Jumlah sekolah dasar negeri mencapai 207, SMPN berjumlah 34 dan SMAN berjumlah 15 sekolah.

Sejalan dengan visi Kota Bekasi "Bekasi Cerdas, Sehat, dan Ihsan", dinas pendidikan Kota Bekasi melaui visinya "Pendidikan Cerdas, Berkualitas, Tahun 2013", berupaya mewujudkan pemerataan pendidikan menuju Manajemen Peningkatan Mutu Berbasis Sekolah (MPMBS), meningkatan mutu pendidikan yang relevan dengan kebutuhan masyarakat melalui peningkatan insentif guru dan mengelola pendidikan secara profesional efektif dan efisien yang berkelanjutan dalam rangka mewujudkan otonomi sekolah.

Sebagai upaya menyelenggarakan pendidikan yang bermutu sebagaimana diamanatkan oleh Undang-Undang Nomor 20 Tahun 2003 tentang Sistem Pendidikan Nasional pada Pasal 50 Ayat (3), yakni: "Pemerintah dan/atau Pemerintah Daerah menyelenggarakan sekurangkurangnya satu satuan pendidikan pada semua jenjang pendidikan untuk dikembangkan menjadi sekolah yang bertaraf internasional". Pemerintah Kota Bekasi menyelenggarakan rintisan sekolah bertaraf internasional (RSBI), dari jenjang SD, SMP dan SMA masing-masing dua sekolah, sesuai dengan kebutuhan masyarakat Kota Bekasi dalam menuju persaingan di tingkat regional, nasional, maupun internasional.

Dalam rangka meningkatkan prestasi kerja guru, pengawasan merupakan perangkat manajemen yang memiliki peranan penting sebagai kontrol layanan guru terhadap pelanggannya (siswa).

Perhatian pemerintah terhadap pendidikan khususnya guru, dapat dilihat dari banyaknya kebijakan seperti : SK Menteri Pendayagunaan Aparatur Negara No. 26/MENPAN/1998 yang memberikan peluang bagi guru untuk kenaikan pangkat sampai golongan ruang IV/e, UU No. 14 Tahun 2005 tentang Guru dan Dosen, yang memberi kesempatan seluruh tenaga pendidik meningkatkan kompetensinya dengan mendapat imbalan khusus berupa tunjangan profesi sebesar satu kali gaji pokok. Kebijakan ini diharapkan dapat memotivasi guru untuk lebih meningkatkan prestasi kerjanya.

Desakan reformasi pendidikan di negeri ini semakin meningkat, pendidikan berkualitas menjadi isu hangat yang harus disikapi dengan arif. Prestasi kerja guru menjadi agenda penting dalam pengembangan sumber daya manusia yang berkualitas. Berdasarkan uraian di atas penulis berpendapat bahwa pengawasan kepala sekolah dan pemberian kompensasi merupakan komponen yang sangat penting untuk menunjang 
prestasi kerja guru dalam kerangka tata laksana organisasi pendidikan. Hal ini terjadi karena prestasi kerja bukan hanya upaya mencapai hasil kerja dalam melaksanakan tugas yang dibebankan kepadanya tetapi juga kualitas kerja yang sangat membutuhkan perencanaan kerja yang baik dan keyakinan untuk mencapai hasil yang maksimal. Untuk mengetahui prestasi kerja guru, kami bermaksud mengadakan penelitian dengan judul "Hubungan Pengawasan dan Kompensasi dengan Prestasi Kerja Guru di SMA Negeri se-Kota Bekasi".

Prestasi Kerja. Prestasi kerja diartikan sebagai proses melakukan pekerjaan dan hasil yang dicapai dari pekerjaan tersebut. Menurut Herfert, prestasi kerja adalah suatu tampilan keadaan secara utuh atas perusahaan selama periode waktu tertentu, sebagai hasil atau prestasi yang dipengaruhi oleh kegiatan operasional perusahaan dalam memanfaatkan sumber-sumber daya yang dimiliki. Ivancevich menyatakan "Job performance includes a number of outcomes". (Prestasi kerja termasuk didalamnya hasil atau keluaran).

Bernardin memberikan definisi tentang performance sebagai berikut: "Performance is defined as the record of autcomes produced on a specified job function or activity during a specified time period ". (Prestasi kerja didefinisikan sebagai catatan mengenai outcome yang dihasilkan dari suatu aktivitas tertentu, selama kurun waktu tertentu pula). Aguinis menerangkan bahwa "Performance is about behavior or what employees do, not about what employees produce or the outcomes of their work". (Prestasi kerja adalah tentang perilaku atau apa yang karyawan lakukan, bukan tentang apa karyawan produksi atau hasil kerja mereka). Selanjutnya Byars dan Rue mendefinisikan prestasi kerja "Performance refers to degree of accomplishment of the tasks that make up an employee's job". (Prestasi kerja mengacu pada tingkat pemenuhan tugas yang membentuk kerja karyawan).

Prestasi kerja mempunyai hubungan yang erat dengan masalah produktivitas, karena merupakan indikator dalam menetukan bagaimana usaha untuk mencapai tingkat produktivitas yang tinggi dalam suatu organisasi. Organisasi perlu mengetahui berbagai kelemahan dan kelebihan pegawai sebagai landasan untuk memperbaiki kelemahan dan menguatkan kelebihan, dalam rangka meningkatkan produktivitas dan pengembangan pegawai. Produktivitas menurut Wahyudi adalah suatu tingkat perbandingan antar besarnya keluaran dengan besarnya masukan.

Jadi dari pernyataan tersebut, telah jelas bahwa untuk mendapatkan gambaran tentang prestasi kerja seseorang, maka perlu pengkajian khusus tentang kemampuan dan kemauan. Pandangan tentang kemampuan seseorang diakui bahwa banyak orang mampu tetapi tidak mau sehingga tetap tidak menghasilkan kinerja yang diharapkan. Demikian halnya banyak orang memiliki kemauan tetapi tidak mampu juga tetap tidak menghasilkan kinerja yang dioptimal.

Berdasarkan uraian di atas maka dapat disintesiskan bahwa prestasi kerja adalah hasil kerja yang dicapai oleh pegawai sesuai dengan tugasnya yang dihubungkan dengan ukuran nilai atau standar tertentu untuk mencapai tujuan organisasi. Adapun indikator dari prestasi kerja dapat dilihat pada: (a) pencapaian tujuan;.(b) ketepatan waktu; (c) umpan balik; (d) inisiatif ; (e) kerja sama.

Pengawasan. Pengawasan atau controlling menurut Daryanto adalah tindakan atau kegiatan usaha agar pelaksanaan pekerjaan serta hasil kerja sesuai dengan rencana, perintah, petunjuk atau ketentuan-ketentuan lainnya yang telah ditetapkan. 
Selanjutnya, Mosley, Megginson dan Pietri mengatakan bahwa "Controlling is defined as the management function that involves comparing actual performance with planed performance and taking corrective action, if needed, to ensure that objective are achieved". (Pengawasan didefinisikan sebagai fungsi manajemen yang melibatkan membandingkan kinerja aktual dengan kinerja yang direncanakan dan mengambil tindakan perbaikan, jika diperlukan, untuk memastikan kondisi objektif yang dicapai).

Gibson, et al. mengatakan "The controlling function includes activities that managers undertake to ensure that actual outcomes are consistent with planned outcomes" (Fungsi pengawasan mencakup kegiatan manajer tentang perjanjian untuk menjamin bahwa hasil yang sebenarnya konsisten dengan hasil yang direncanakan). Robbins dan Coulter mengatakan "Control is process of monitoring, comparing, and correcting work performance" (Kontrol adalah proses pemantauan, membandingkan, dan memperbaiki kinerja).

Pengawasan pada dasarnya diarahkan untuk menghindari adanya kemungkinan penyelewengan atau penyimpangan atas tujuan yang akan dicapai. Melalui pengawasan diharapkan dapat menciptakan suatu aktivitas yang berkaitan erat dengan penentuan atau evaluasi mengenai sejauh mana pelaksanaan kerja sudah dilaksanakan. Pengawasan adalah proses mengevaluasi pelaksanaan kerja dengan membandingkan pelaksanaan aktual dengan apa yang diharapkan (goals dan objectives) serta mengambil tindakan yang perlu. Sedangkan Siagian mengatakan bahwa pengawasan merupakan upaya yang sistematik untuk mengamati dan memantau berbagai fungsi, aktivitas dan kegiatan yang terjadi dalam organisasi sesuai dengan rencana yang telah ditetapkan sebelumnya.

Dalam konteks pengawasan mutu pendidikan, kepala sekolah dalam melaksanakan aktivitasnya hendaknya menjauhkan diri dari sifat otoriter, hubungan guru dengan kepala sekolah bukan hubungan hierarkis antara atasan dan bawahan tetapi juga sebagai mitra kerja. Oleh karena itu dalam melaksanakan pengawasan mengedepankan prinsip-prinsip: (1) menciptakan hubungan kemanusiaan yang harmonis; (2) berkesinambungan; (3) demokratis;.(4) integral dengan program pendidikan; (5) komprehensif; (6) konstruktif; (7) obyektif;.

Berdasarkan uraian di atas dapat disintesiskan bahwa pengawasan adalah proses membandingkan antara perilaku nyata dengan perilaku yang direncanakan agar para pegawai dapat melaksanakan pekerjaannya sesuai dengan hasil yang diinginkan. Dengan memikian indikatori dari pengawasan dalam penelitian ini adalah: (a) penilaian berdasarkan standar kerja; (b) pemantauan hasil kerja; (c) pencapaian target kerja; (d) tindakan perbaikan.

Kompensasi. Pada dasarnya manusia bekerja untuk memperoleh pendapatan yang berupa uang agar terpenuhi kebutuhan hidupnya. Dengan demikian seorang karyawan menghargai kerja keras dan menunjukkan loyalitas terhadap perusahaan agar memberikan penghargaan terhadap prestasi kerja karyawan yaitu dengan jalan memberikan kompensasi. Menurut Ivancevich "Compensation is human recourse management function that deals with every type of reward individuals receive in exchange for performing organizational tasks". (Kompensasi adalah manajemen sumber daya manusia yang berhubungan dengan setiap jenis penghargaan individu, sebagai bentuk penerimaan dan imbalan untuk melaksanakan tugas-tugas organisasi). 
Bernardin mengatakan" The term compensation refers to all form of financial return and tangible benefits that employees receive as part of an employment relationship". (Kompensasi merujuk pada segala bentuk pengembalian keuangan dan manfaat nyata bahwa karyawan menerima sebagai bagian dari hubungan kerja).

Pendapat lain mengenai kompensasi disampaikan oleh Dessler yang mengatakan bahwa kompensasi adalah semua bentuk pembayaran atau imbalan bagi karyawan dan muncul dari pekerjaan mereka. Sejalan dengan pendapat tersebut Sedarmayanti mengatakan bahwa kompensasi adalah segala sesuatu yang diterima oleh pegawai sebagai balas jasa untuk kerja mereka.

Efendi Hariandja mendefinisikan kompensasi adalah keseluruhan balas jasa yang diterima oleh pegawai sebagai akibat dari pelaksanaan pekerjaan di organisasi dalam bentuk uang atau lainnya, yang dapat berupa gaji, upah, bonus, insentif, dan tunjangan lainnya seperti tunjangan hari raya, uang makan, uang cuti, dan lain-lain.

Bentuk pemberian kompensasi menurut Mcshane dan Glinow adalah: (1) Membership and seniority based reward; (2) Job status based reward; (3) Competency based reward; (4) Performance based reward. Pemberian kompensasi meliputi : pendekatan keanggotaan organisasi dan senioritas, pendekatan pekerjaan/jabatan, pendekatan kompetensi pegawai, dan pendekatan kinerja.

Pemberian kompensasi dalam suatu organisasi merupakan faktor penting agar perusahaan mencapai tujuan dengan baik. Hal ini disampaikan oleh Gibson, et all, "The main objectives of reward are (1) to attract qualified people the organization, (2) to keep employees coming to work, and (3) to motivate employees to achieve high level of performance". Tujuan utama pemberian penghargaan adalah; menarik orang yang bermutu untuk bergabung dalam organisasi, menjaga pekerja agar datang untuk bekerja, dan memotivasi pegawai meningkatkan kinerjanya.

Berdasarkan uraian di atas dapat disintesiskan bahwa kompensasi adalah imbalan yang diberikan oleh lembaga kepada pegawai, baik dalam bentuk uang, barang maupun jabatan atas pekerjaan yang dilakukannya terhadap organisasi. Dengan demikian indikatori kompensasi dalam penelitian ini adalah: (a) pemberian gaji; (b) pemberian insentif; (c) pemberian tunjangan; (d) kesempatan promosi.

\section{METODE}

Metode penelitian yang akan digunakan dalam penelitian ini adalah metode survei dengan teknik penelitian korelasional. Populasi sasaran, yaitu guru-guru SMA Negeri se-Kota Bekasi yang berstatus Pegawai Negeri Sipil dengan jumlah 821 orang.

Menentukan populasi terjangkau yaitu guru-guru yang terdapat di sekolah yang akan dijadikan objek penelitian, yaitu lima SMA Negeri dengan jumlah 286 orang guru sebagai kerangka sampel. Sampel penelitian ini adalah guru-guru yang ada di Kota Bekasi yang diambil secara acak sederhana dengan menggunakan rumus Slovin. Tempat yang digunakan dalam penelitian ini adalah SMA Negeri se-Kota Bekasi. Adapun waktu pelaksaan penelitian ini pada bulan Mei s.d. Juni 2011.

\section{HASIL PENELITIAN DAN PEMBAHASAN}

\section{Hubungan Pengawasan dengan Prestasi Kerja}

Dari hasil análisis korelasi antara pengawasan dengan prestasi kerja, diperoleh koefisien korelasi product moment sebesar 0,668 $\left(\mathrm{r}_{\mathrm{y} 1}=0,668\right)$. Nilai ini memberikan pengertian bahwa keterikatan antara Pengawasan dengan Prestasi Kerja adalah 
signifikan atau positif. Artinya, semakin tinggi Pengawasan, akan semakin tinggi pula Prestasi Kerja.

Sedangkan koefisien determinasi diperoleh dari kuadrat koefisien korelasi antara Pengawasan (X1) dengan Prestasi Kerja (Y) yaitu sebesar $r_{y 1}{ }^{2}=0,4462$. Ini menunjukkan bahwa 44,62 \% Prestasi Kerja dapat ditentukan oleh Pengawasan. Selanjutnya untuk mengetahui keeratan hubungan antara Pengawasan $\left(X_{1}\right)$ dengan Prestasi Kerja $(Y)$ secara parsial perlu dilakukan pengontrolan pengaruh variabel Kompensasi $\left(\mathrm{X}_{2}\right)$ terhadap Prestasi Kerja $(\mathrm{Y})$ dengan koefisien korelasi parsial $=0,330$. Hasil penelitian ini sejalan dengan teori yang dikemukakan oleh Mullins : Elements of an organisational control system (sistem kontrol organiasi): (a) Planning what is desired (perencanaan yang diharapkan); (b) Establishing standards of performance (menentukan standar kinerja); (c) Monitoring actual performance (pemantauan hasil kinerja); (d) Comparing actual achievement against the planned target (membandingkan antara prestasi dengan target yang direncanakan); (e)Rectifying and taking corrective action (meralat dan memberikan tindakan korektif).

\section{Hubungan Kompensasi dengan Prestasi Kerja}

Dari hasil analisis korelasi antara kompensasi dengan prestasi kerja dapat diperoleh koefisien korelasi product moment sebesar $\mathrm{r}_{\mathrm{y} 2}=0,717\left(\mathrm{r}_{\mathrm{y} 2}=0,717\right)$. Nilai ini memberikan pengertian bahwa keterikatan antara Kompensasi dengan Prestasi Kerja adalah signifikan atau positif. Artinya, semakin tinggi Kompensasi, akan semakin tinggi pula Prestasi Kerja.

Sedangkan koefisien determinasi diperoleh dari kuadrat koefisien korelasi antara Kompensasi $\left(\mathrm{X}_{2}\right)$ dengan Prestasi Kerja $(\mathrm{Y})$ yaitu sebesar $\mathrm{r}_{\mathrm{y} 2}{ }^{2}=0,5141$. Ini menunjukkan bahwa 51,41\% Prestasi Kerja dapat ditentukan oleh Pengawasan.

Selanjutnya untuk mengetahui keeratan hubungan antara Pengawasan $\left(X_{1}\right)$ dengan Prestasi Kerja (Y) secara parsial perlu dilakukan pengontrolan pengaruh variabel Kompensasi $\left(\mathrm{X}_{2}\right)$ terhadap Prestasi Kerja $(\mathrm{Y})$ dengan koefisien korelasi parsial = 0,466 . Hasil penelitian ini sesuai dengan teori yang dikemukakan oleh, Slocum dan Hellriegel : The ability of rewards to motivate individuals or team to high performance was found to depens on six factors 1) availability; 2) timeliness; 3) performance contingency; 4) durability; 5) equity; 6) visibility". (Kemampuan memberikan penghargaan dapat memotivasi individu atau tim

agar berkinerja tinggi, hal ini bergantung pada enam faktor berikut: ketersediaan, ketepatan waktu, kemungkinan berkinerja, daya tahan, keadilan, dan dapat dilihat).

\section{Hubungan Pengawasan dan Kompensasi dengan Prestasi Kerja}

Hasil analisis korelasi ganda antara pengawasan dan kompensasi dengan prestasi kerja, diperoleh koefisien korelasi ganda sebesar $0,753\left(\mathrm{r}_{\mathrm{y} \cdot 12}=0,753\right)$. Dengan demikian, terdapat hubungan positif dan signifikan antara Pengawasan dan Kompensasi secara bersama-sama dengan Prestasi Kerja. artinya semakin tinggi Pengawasan dan Kompensasi, semakin tinggi pula Prestasi Kerja.

Dari koefisien korelasi ganda di atas, diperoleh koefisien determinasi hubungan antara Pengawasan $\left(X_{1}\right)$ dan Kompensai $\left(X_{2}\right)$ secara bersama-sama dengan Prestasi Kerja (Y) sebesar $(0,753)^{2}=0,5669$. Hal ini menunjukkan 56,69 \% variasi variabel Prestasi Kerja $(Y)$ dapat dijelaskan oleh variabel Pengawasan $\left(X_{1}\right)$ dan Kompensai $\left(X_{2}\right)$ yang secara bersama-sama memberikan sumbangan efektif sebesar 56,69\% . 
Hasil penelitian ini sesuai dengan teori yang dikemukakan oleh, Kreitner dan Kinicki : Performance management is an organization wide system whereby managers integrate the activities of goal setting, monitoring and evaluating, providing feedback and coaching, and rewarding employees on a continous basis. (Manajemen kinerja merupakan sistem organisasi yang luas dimana manajer mengintegrasikan kegiatan penetapan tujuan, monitoring dan evaluasi, memberikan umpan balik dan pelatihan, dan penghargaan karyawan secara berkesinambungan).

\section{PENUTUP}

Kesimpulan: 1) Terdapat hubungan positif antara pengawasan dengan prestasi kerja. Hal ini dapat dilihat dari derajat kekuatan hubungan dalam bentuk koefision korelasi dan koefisisien determinasi. 2) Terdapat hubungan positif antara kompensasi dengan prestasi kerja, yang ditentukan oleh derajat kekuatan hubungan dalam bentuk koefisien korelasi dan koefisien determinasi. Nilai koefiesien determinasi ini menentukan seberapa besar varians prestasi kerja ditentukan oleh variabel kompensasi. 3) Terdapat hubungan positif antara pengawasan dan kompensasi secara bersamasama dengan prestasi kerja yang ditentukan oleh derajat kekuatan hubungan dalam bentuk koefisien korelasi ganda dan koefisien determinasi jamak. Nilai koefisien determinasi ini menentukan seberapa besar varians prestasi kerja ditentukan oleh variabel pengawasan dan variabel kompensasi secara bersama-sama.

Implikasi: Pertama, untuk meningkatkan prestasi kerja melalui pengawasan yang efektif dengan cara melakukan penilaian berdasarkan standar kerja, pemantauan hasil kerja, pencapaian target kerja dan tindakan perbaikan. Kedua, untuk meningkatkan prestasi kerja melalui pemberian kompensasi yang memadai dengan cara pemberian gaji, pemberian insentif, pemberian tunjangan, dan kesempatan promosi.

Saran: 1) Kepala Sekolah hendaknya menyusun rencana dan prosedur kerja, membangun kerja sama dengan para guru untuk mencapai tujuan organisasi yang diharapkan. 2) Kepala Sekolah agar senantiasa mendorong guru untuk meningkatkan prestasi kerjanya, memberi keleluasaan kepada para guru untuk berinovasi dan berkreasi dalam menjalankan tugasnya sehingga guru dapat berkarir secara maksimal. 3) Kepala Sekolah harus berusaha membuat situasi dan lingkungan kerja yang harmonis serta stabil, sehingga para guru dapat menjaga prestasi kerjanya dengan baik . 4) Berkaitan dengan kompensasi, para guru dalam menjalankan aktivitasnya tidak sematamata karena penghargaan yang diberikan kepadanya melainkan tanggung jawab moral dan profesional kepada peserta didik. Namun demikian, kepala sekolah senantiasa memperhatikan hak-hak dasar para guru agar dapat melaksanakan tugasnya dengan baik.

\section{DAFTAR PUSTAKA}

Aguinis, Herman. Performance Management. New Jersey: Pearson Prentice, 2009.

Bernardin, H. John. Human Resource Management. New Jersey:Pearson Prentice, 2003.

Byars Lloyd L. and Rue Leslie W. Human Resource Management. New York: McGraw- 
Hill/Irwin,2008

Daryanto, H. M. Administrasi Pendidikan. Jakarta:Rineka Cipta, 2010

Dessler,Gary. Manajemen Sumber Daya Manusia . New Jersey:Florida International University, 2003

Gibson,James L. et al. Organizations : Behavior Structure Processes. Boston: Mc Graw Hill, 2006

Gibson,James L. .et al. Organizations. New York: McGraw-Hill, 2006

Ivancevich, John M. Human Resource Management New York: Mc Graw Hill, 2007

Ivancevich,.John M. et al. Organizational Behavior and Management..New York:McGrawHill,

2008

John W. Slocum dan Don Hellriegel, Fundamental of Organizational Behavior.

China:Thomson, 2007

Kreitner, Robert dan Kinicki, Angelo. Organizational Behavior. New York:McGrawHill,2007

McShane, Steven L and Glinow,. Mary Ann Von Organizational Behavior. New York: : McGraw-Hill, 2010

Mosley, Donald C. et al. .Supervisory Management. South Western:Thomson, 2005

Mullins, Laurie J. Managemen and Organisational Behavior. Eighth Edition.

England:Prentice

Hall,2007

Rivai, Veithzal dan Sagala, Ella Jauvani Manajemen Sumber Daya Manusia. untuk

Perusahaan. Jakarta:Raja Grafindi Persada, 2009.

Robbins, Stephen P. and Coulter, Mary Management New Jersey: Pearson Prentice Hall, 2007

Terry, G.R and Rue L.W. Dasar-Dasar Manajemen, terjemahan G.A. Ticoalu Jakarta: Bumi Aksara,2008

Wahyudi. Kepemimpinan Kepala Sekolah dalam Organisasi Pembelajar Bandung :

Alfabeta,2009 